\title{
Original Research \\ Predictions of Select Control Organic Pollutant Removal in Subsurface Flow Wetlands
}

\author{
Danyu Xu', ${ }^{1,2}$ Yan Shi ${ }^{1,2 * *}$, Yunxia Duan', Yuangang Wang ${ }^{1}$, \\ Yangyang You ${ }^{2}$, Ang Yang ${ }^{2}$, Ying Hou $^{2}$ \\ ${ }^{1}$ Tianjin Academy of Environmental Science, Tianjin 300191, China \\ ${ }^{2}$ Tianjin United Environmental Engineering Design Company Limited, Tianjin 300191, China \\ Received: November 17, 2014 \\ Accepted: August 27, 2015
}

\begin{abstract}
The migration and transformation model was established to represent organic pollutant flow patterns in a subsurface flow wetland (SSFW). In order to simulate internal flow field and water quality concentration in a wetland system simultaneously, the porous media model coupled with a Monod equation were introduced to describe hydraulic characteristics and biodegradation. The parameters of the model were tested and verified by a series of experiments. The result showed that this model could reasonably simulate organic pollutant removal in SSFW. Theoretically, a backwater zone and rapid channel would appear in SSFW of different substrate filler, which could influence hydraulic efficiency and pollutant removal effects. Seven kinds of typical organic pollutants were selected, and the ranking of their removal efficiency was in the order of aminobenzene, phenol, dimethylbenzene, toluene, benzene, nitrobenzene, and chlorobenzene. The treatment effects of select control organic pollutants could be improved by extending the retention time and increasing adsorption quantity through further filler optimization.
\end{abstract}

Keywords: subsurface flow constructed wetlands, porous media model, selecte control organic pollutants, biodegradation, numerical simulation

\section{Introduction}

Subsurface flow constructed wetlands (SSFW) have been widely applied in treating wastewaters of different types. They are not only suitable for nutrient element removal (such as nitrogen and phosphorus), but also have been applied to degradation of organic pollutants. In recent years, a lot of research has been carried out at home and abroad, and most of them are about the removal of ordinary organic pollutants in urban sewage and agricultural runoff by wetlands [1-3]. With the development of industry, more and more SSFWs have been applied in the advanced treatment and purification of standard industrial wastewater from industrial zones, such as the Constructed

*e-mail: shiyan800712@126.com
Wetland of Shanghai Chemical Industry Zone and the Constructed Wetland of Tianjin Lingang Industry Zone.

Since industrial wastewater is complex and often contains a variety of toxic, carcinogenic, and teratogenic organic compounds that may affect human health and water quality of receiving water bodies, 35 species of organic compounds in addition to COD are in the list of the select control pollutants based on the Discharge Standard of Pollutants for Municipal Wastewater Treatment Plant (GB18918-2002) and Integrated Wastewater Discharge Standard (GB8978-1996). Now, Quantitative research on degradation of selected control pollutants by constructed wetlands are rare. And most existing research only involves several kinds of pollutants in the list, such as benzene $[4,5]$, polychlorinated biphenyls (PCBS) [6], polycyclic aromatic hydrocarbons [7], and so on. 
The main reason has two aspects. On one hand, the biodegradation of persistent organic pollutants (POPs) in constructed wetlands is slow and complicated, and the cycle of the experiment is too long and too difficult to carry out. On the other hand, analysis about the degradation process of select control pollutants in the wetland lacks accurate and practical mathematical models, and the existing several types of typical wetland models (such as the "Black box," attenuation, first-order kinetic, and ecological dynamics models) and relevant commercial software (such as CW2D model, MIKE21, and SMS surface water model) are also mainly used for study of conventional organic pollutants [8-11].

As is well known, the removal of organic pollutants by constructed wetlands is mainly due to the combined action of multiple components, including plants, soil, and microbes, and biodegradation and substrates adsorption play a core role in removing organic pollutants $[12,13]$. Since general wetland plants primarily remove organic pollutants through microbes around the root in the soil, our paper mainly focused on the effects of adsorption, microbial degradation, and hydraulic characteristics. Our main research work included the following aspects: establishing a mathematical model that could quantitatively describe the migration and removal processes of organic pollutants in the subsurface flow wetland, screened typical selected control pollutants and verified the model parameters, and tested the wetlands to validate the mode. Meanwhile, it also analyzed subsurface hydraulic and concentration changes in the subsurface flow wetlands that were of different fillers, and predicted the removal efficiencies of typical select control pollutants, hoping to provide scientific data and technology methods for study of the removal of select control pollutants by wetland.

\section{Mathematical Model}

\section{Buildup of Model}

The mass transfer model was adopted to realize coupled simulation that combined hydraulics with degradation and adsorption processes of pollutants. The hydraulics model selected a porous media model to simulate the porous media flow in subsurface flow wetland [14], and assumed that flow and mass transfer of contaminants in wetland substrate was conducted under constant temperature without moisture loss of substrate. Removal of organic pollutants took only biodegradation and filler adsorption into consideration. The description of the model was as follows:

1. Continuity equation

$$
\frac{\partial \rho}{\partial t}+\frac{\partial}{\partial x_{i}}\left(\rho u_{i}\right)=S_{m}
$$

2. Porous medium momentum equation

$$
\frac{\partial}{\partial t}\left(\rho u_{i}\right)+\frac{\partial}{\partial x_{j}}\left(\rho u_{i} u_{j}\right)=-\frac{\partial P}{\partial x_{i}}+\frac{\partial \tau_{i j}}{\partial x_{j}}+\rho g_{i}+S_{i(2)}
$$

3. Mass transfer model

$$
\frac{\partial C_{i}}{\partial t}+\nabla \cdot\left(C_{i} \vec{u}\right)=\nabla \cdot\left(\operatorname{\Gamma grad}\left(C_{i}\right)\right)+r_{i}
$$

In equation (1), $\rho$ is fluid density, $u_{i}$ is the axial components of velocity, and $S_{m}$ is the source item. In equation (2), $\tau_{i j}$ is tangential stress, and an auxiliary momentum loss source term $\left(S_{i}\right)$ was added to the porous media momentum conservation equation based on the momentum equation. Assuming the filler was isotropic medium of uniform diameter and porosity, it could be expressed as:

$$
S_{i}=-\left(\frac{\mu}{\alpha} u_{i}+C_{2} \frac{1}{2}\left|u_{i}\right| u_{i}\right)
$$

For fill form of different types within a wide range of Reynolds number, it could be expressed as:

$$
\alpha=\frac{d_{p}^{2}}{150} \frac{\varepsilon^{2}}{(1-\varepsilon)^{2}}, \quad C_{2}=\frac{3.5}{d_{p}} \frac{(1-\varepsilon)}{\varepsilon^{2}},
$$

$\ldots$ where $d_{p}$ is the average diameter of substrates, $1 / \alpha$ is the viscous resistance coefficient, $C_{2}$ is the inertia resistance coefficient, and $\varepsilon$ is the porosity of substrates. In equation 3 , $C_{i}$ is the quality concentration of pollutants component $i$ in the liquid phase. $\frac{\partial C_{i}}{\partial t}, \nabla \cdot\left(C_{i} \vec{u}\right), \nabla \cdot\left(\operatorname{\Gamma grad}\left(C_{i}\right)\right), r_{i}$ represented the change rate of time, the convection term, the diffusion term and the reaction term, respectively. The reaction term mainly contained microbial degradation and adsorption. The Monod equation could be used for biodegradation, namely $\frac{d C_{i}}{d t}=-\frac{q_{1} C_{i}}{K_{S}+C_{i}}$. A partial equilibrium model was used for adsorption mass transfer between solid and liquid, and solid-liquid adsorption equilibrium coincided with the linear adsorption equilibrium relation, namely $r_{i}=K_{d} \frac{\partial C_{i}}{\partial t}+\frac{\mu_{i} C_{i}}{K_{s}+C_{i}}$, with $K_{d}$ representing the adsorption constants, $K_{s}$ representing the substrates half-saturationconstants, and $\mu_{i}$ being the maximum specific growth rate.

\section{Boundary Conditions}

1. Inlet: the laws of conservation of mass and irrotational assumption were adopted, and assumed that the flow rate was of uniform distribution.

2. Outlet: the overflow assumption was adopted, and assumed that the outlet pressure was an atmospheric pressure; the flow was similar to free outflow.

3. Bottom and wall: the wall function method was adopted.

4. Water distribution, purification area and catchment areas: the internal boundary was adopted [15].

5. Model parameters (Table 1). 
Table 1. Model parameters.

\begin{tabular}{|l|c|c|c|c|}
\hline \multirow{2}{*}{$\begin{array}{c}\text { Parameters } \\
\text { of filler layer }\end{array}$} & \multicolumn{4}{|c|}{ Material } \\
\cline { 2 - 5 } & Gravel & Sand & Slag & Coal ash \\
\hline$d_{p}[\mathrm{~mm}]$ & 20 & 3 & 7.3 & 3.5 \\
\hline$\varepsilon$ & 0.36 & 0.4 & 0.39 & 0.51 \\
\hline $1 / \alpha\left[\mathrm{m}^{-2}\right]$ & $1.18 \times 10^{6}$ & $3.75 \times 10^{7}$ & $5.33 \times 10^{7}$ & $6.42 \times 10^{7}$ \\
\hline$C_{2}\left[\mathrm{~m}^{-1}\right]$ & $2.4 \times 10^{3}$ & $1.09 \times 10^{4}$ & $1.89 \times 10^{4}$ & $2.16 \times 10^{5}$ \\
\hline
\end{tabular}

\section{Solution Method for Model}

Simulation was carried out through computational fluid dynamics software (Fluent), the empirical equation of the Monod model was edited by language $\mathrm{C}$ and introduced into the hydrodynamic model through user-defined function (UDF) in the software, to realize model coupling of hydraulics and reaction kinetics.

\section{Model Application}

The calculation prototypes were three sets of constructed wetland test system that were of the same size (Fig. 1; $\mathrm{L} \times \mathrm{W} \times \mathrm{H}: 2 \times 1.2 \times 0.8 \mathrm{~m})$. The wetlands were filled with sand, backfill, and ash, with gravel at the bottom. Select secondary standard effluent of comprehensive sewage plant in a chemical industrial park of Tianjin as influent of wetland system, the main water quality parameters were COD: $115 \sim 140 \mathrm{mg} / \mathrm{L}, \mathrm{TN}: 7.8 \sim 9.1 \mathrm{mg} / \mathrm{L}$, TP: $1.4 \sim 1.6 \mathrm{mg} / \mathrm{L}$. The chemical industrial park was a national petrochemical installation, its wastewater contained a variety of select control pollutants listed in GB8978-1996. In a petroleum and chemical industry chain, the refining process upstream often generated wastewater containing petroleum pollutants such as toluene and xylene, while wastewater from soda and chemical plants in the middle mainly contained aniline, chlorophenol, and so on. So aniline, phenol, benzene, toluene, xylene, nitrobenzene, and chlorobenzene were selected as study objects. Analysis of organic pollutants was entrusted to the unit that had an aptitude for testing.

\section{Model Verification and Validation}

\section{Identification of Model Parameters}

\section{Geometric Parameters of Filler Layer}

In the artificial wetland testing system, average particle size, porosity, viscous resistance coefficient, inertia resistance coefficient, and other parameters of sand, slag, fly ash, and gravel are shown in Table 1. The average particle size and porosity were measured by sieving method and a porosity measuring instrument, respectively. Resistance coefficient was obtained by permeability test. The details are in Fig. 1.

\section{Adsorption Parameters}

The process of substrate adsorption was complex. The most common isothermal adsorption included Linear equilibrium adsorption, Freundlich equilibrium adsorption, Langmiur equilibrium adsorption, Temkin equilibrium adsorption, and so on [16-18]. Many existing studies show that Linear equilibrium adsorption had the best correlation during pollutant adsorption in the substrate layer [19-21]. Therefore, the Linear equilibrium adsorption model was used in this paper. To determine parameters of the linear equilibrium adsorption model, the steps were as follows:

1. A series of samples with different solid-liquid weight ratio were prepared in airtight containers.

2. We measured the initial concentrations of toxic and organic pollutants and put them into a rotary shaker under certain conditions (constant temperature $20^{\circ} \mathrm{C}$, rotational speed $130 \mathrm{rpm}$ ) until the adsorption achieved equilibrium.

3. According to the pollutant concentrations in liquid and solid phases, we drew the adsorption isotherm to determine the adsorption parameters of the model according the slope of lines. The model parameters are shown in Table 2.

\section{Biodegradation Parameters}

A batch reactor method was used to determine the biodegradation parameters. The bacteria source was from the biochemical pool of a comprehensive sewage plant in the chemical industrial park. Nutritional liquid and bacterial suspensions liquid were added into the batch reactor after domestication, then we added specific pollutants with a syringe after about 10 minutes of sufficient aeration. Then we put them into a freezing and constant-temperature rotary shaker under certain conditions (constant temperature $20^{\circ} \mathrm{C}$, rotational speed $150 \mathrm{rpm}$ ). The concentration of pollutants was detected by gas chromatography at regular intervals. We drew a curve of time and concentration of pollutants, and then determined the biodegradation parameters of the model (Table 3).

\section{Validation of Model}

The influent of the wetland system was secondary standard effluent of a comprehensive sewage plant in the chemical industrial park. Each experiment lasted for two weeks, average daily flow was $1.5 \mathrm{~m}^{3}$, and average COD concen-

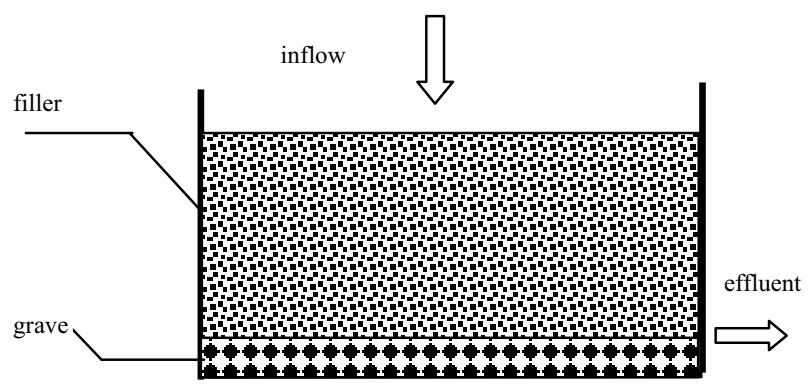

Fig. 1. Subsurface flow wetland (SSFW) system structure. 
Table 2. Adsorption constant of the typical organic pollutions with different fillers (the unit of equilibrium constant is $\times 10^{-3} \mathrm{~m}^{3} / \mathrm{kg}$ ).

\begin{tabular}{|l|c|c|c|c|c|c|c|c|}
\hline \multicolumn{1}{|c|}{ Species } & Parameters & Aniline & Phenol & Xylene & Toluene & Benzene & Nitrobenzene & Chlorobenzene \\
\cline { 1 - 9 } Sand & \multirow{3}{*}{$r_{i}$} & 0.79 & 0.56 & 0.34 & 0.13 & 0.1 & 0.09 & 1.7 \\
\cline { 1 - 9 } Backfill & 3.67 & 3.31 & 2.927 & 2.17 & 1.92 & 1.75 & 1.2 \\
\cline { 1 - 7 } Coal ash & & 3.98 & 365 & 3.45 & 2.89 & 2.12 & 1.83 & 1.32 \\
\hline
\end{tabular}

Table 3. Degradation parameters of typical organic pollutants.

\begin{tabular}{|l|c|c|c|c|c|c|c|}
\hline Parameters/pollutants & Xylene & Aniline & Phenol & Nitrobenzene & Benzene & Chlorobenzene & Toluene \\
\hline The half-life $[\mathrm{d}]$ & 5.5 & 2 & 4 & 56 & 35 & 240 & 28 \\
\hline$\mu_{i}\left[\mathrm{~h}^{-1}\right]$ & 0.0356 & 0.0224 & 0.0268 & 0.0038 & 0.0092 & 0.0001 & 0.0348 \\
\hline$K_{s}[\mathrm{mg} / \mathrm{L}]$ & 0.089 & 0.056 & 0.067 & 0.0097 & 0.023 & 0.0003 & 0.087 \\
\hline
\end{tabular}

tration was about $58 \mathrm{mg} / \mathrm{L}$. We selected the concentration of select control pollutants as object, and monitored average daily concentrations in the influent and effluent of wetlands, which were filled with different fillers. We also compared simulation values with the measured values, while measured values were the average influent water quality during the experiment, simulation values were the results in the situation that the influent was steady. From Table 4 it could be found that the simulation values agreed well with the measured values and the relative error of the model was between $-0.34 \%$ and $3.55 \%$, indicating that the model could reflect the actual water quality changes in the wetland system effectively.

\section{Results and Discussion}

\section{The Flow Field Distribution in the Wetlands of Different Fillers}

In the aspect of flow characteristics, according to Figs. $4 \mathrm{a}$ and $4 \mathrm{~b}$, the streamline distribution at the inlet of the upper left was intensive, and the flow velocity was of fan- shaped distribution and decreased gradually, entering into gravel layer of lower left from the field at the upper left of fine sand, slag, and fly ash layers, respectively. Since medium resistance of gravel was small, the water flowed out fast at the bottom, and the speed increased as it approached the outlet. However, the streamline distribution at the upper part of the fine sand and slag layers were sparse, and the water flowed slowly and was collected by the medium of the lower, then flowed outside. In Fig. 4a, the dark blue area in the upper right corner indicated the flow velocity was less than $7.5 \times 10^{-5} \mathrm{~m} / \mathrm{s}$, flow speed was relatively slow, so it could be called backwater region. When water flowed through sand, slag and fly ash, the inertia and viscous resistance were different, so the backwater region may appear in different positions. In Fig. 4b, the flow velocity in the set layer at the lower right was relatively fast and formed a rapid channel. The average residence time would be shortened because of backwater region and the rapid channel, which may reduce the hydraulic efficiency of constructed wetlands in a certain extent, thus affecting the removal efficiency of pollutants. Therefore, the distribution of the flow field could be improved by optimizing the water distribution condition.

Table 4. Measurement and verification of typical organic pollutants.

\begin{tabular}{|c|c|c|c|c|c|c|c|c|c|c|}
\hline \multirow{3}{*}{ Pollutants } & \multirow{3}{*}{$\begin{array}{c}\text { Average } \\
\text { concentration } \\
\text { in influent } \\
{[\mathrm{mg} / \mathrm{L}]}\end{array}$} & \multicolumn{9}{|c|}{ Concentration in effluent $[\mathrm{mg} / \mathrm{L}]$} \\
\hline & & \multicolumn{3}{|c|}{ Gravel and fine sand } & \multicolumn{3}{|c|}{ Gravel and slag } & \multicolumn{3}{|c|}{ Gravel and coal ash } \\
\hline & & $\begin{array}{c}\text { Measured } \\
\text { value }\end{array}$ & $\begin{array}{c}\text { Simulation } \\
\text { value }\end{array}$ & $\begin{array}{c}\text { Relative } \\
\text { error }\end{array}$ & $\begin{array}{c}\text { Measured } \\
\text { value }\end{array}$ & $\begin{array}{l}\text { Simulation } \\
\text { value }\end{array}$ & $\begin{array}{c}\text { Relative } \\
\text { error }\end{array}$ & $\begin{array}{c}\text { Measured } \\
\text { value }\end{array}$ & $\begin{array}{l}\text { Simulation } \\
\text { value }\end{array}$ & $\begin{array}{c}\text { Relative } \\
\text { error }\end{array}$ \\
\hline Benzene & 0.1 & 0.092 & 0.091 & $1.09 \%$ & 0.091 & 0.089 & $2.25 \%$ & 0.09 & 0.092 & $-2.22 \%$ \\
\hline Toluene & 0.1 & 0.086 & 0.0842 & $2.09 \%$ & 0.085 & 0.086 & $-1.16 \%$ & 0.084 & 0.082 & $2.38 \%$ \\
\hline Xylene & 0.4 & 0.338 & 0.326 & $3.55 \%$ & 0.335 & 0.329 & $1.82 \%$ & 0.33 & 0.327 & $0.91 \%$ \\
\hline Aniline & 0.5 & 0.381 & 0.373 & $2.10 \%$ & 0.375 & 0.388 & $-3.35 \%$ & 0.367 & 0.365 & $0.54 \%$ \\
\hline Phenol & 0.3 & 0.245 & 0.238 & $2.86 \%$ & 0.244 & 0.239 & $2.09 \%$ & 0.235 & 0.243 & $-3.40 \%$ \\
\hline Nitrobenzene & 0.5 & 0.481 & 0.469 & $2.49 \%$ & 0.478 & 0.469 & $1.92 \%$ & 0.473 & 0.461 & $2.54 \%$ \\
\hline Chlorobenzene & 0.3 & 0.299 & 0.291 & $2.68 \%$ & 0.298 & 0.29 & $2.76 \%$ & 0.297 & 0.291 & $2.02 \%$ \\
\hline
\end{tabular}


Table 5. Forecasting of typical pollutant removal in SSFW.

\begin{tabular}{|c|c|c|c|c|c|c|c|c|c|c|}
\hline \multirow{3}{*}{ No. } & \multirow{3}{*}{ Pollutants } & \multicolumn{9}{|c|}{ Removal rate } \\
\hline & & \multicolumn{3}{|c|}{ Gravel and fine sand } & \multicolumn{3}{|c|}{ Gravel and slag } & \multicolumn{3}{|c|}{ Gravel and coal ash } \\
\hline & & $\begin{array}{c}\text { Absorption } \\
\text { removal }\end{array}$ & $\begin{array}{c}\text { Biological } \\
\text { removal }\end{array}$ & $\begin{array}{l}\text { Total } \\
\text { removal }\end{array}$ & $\begin{array}{l}\text { Absorption } \\
\text { removal }\end{array}$ & $\begin{array}{c}\text { Biological } \\
\text { removal }\end{array}$ & $\begin{array}{c}\text { Total } \\
\text { removal }\end{array}$ & $\begin{array}{l}\text { Absorption } \\
\text { removal }\end{array}$ & $\begin{array}{c}\text { Biological } \\
\text { removal }\end{array}$ & $\begin{array}{l}\text { Total } \\
\text { removal }\end{array}$ \\
\hline 1. & Toluene & $0.60 \%$ & $15.96 \%$ & $16.56 \%$ & $0.71 \%$ & $16.21 \%$ & $16.92 \%$ & $0.73 \%$ & $17.31 \%$ & $18.04 \%$ \\
\hline 2. & Benzene & $0.46 \%$ & $9.48 \%$ & $9.94 \%$ & $0.53 \%$ & $9.41 \%$ & $9.94 \%$ & $0.59 \%$ & $10.41 \%$ & $11.00 \%$ \\
\hline 3. & Nitrobenzene & $0.42 \%$ & $3.49 \%$ & $3.91 \%$ & $0.52 \%$ & $4.10 \%$ & $4.62 \%$ & $0.58 \%$ & $5.10 \%$ & $5.68 \%$ \\
\hline 4. & Aniline & $3.66 \%$ & $27.69 \%$ & $31.35 \%$ & $4.26 \%$ & $29.21 \%$ & $33.47 \%$ & $4.96 \%$ & $31.21 \%$ & $36.17 \%$ \\
\hline 5. & Phenol & $2.59 \%$ & $19.99 \%$ & $22.58 \%$ & $2.59 \%$ & $20.12 \%$ & $22.71 \%$ & $3.59 \%$ & $24.12 \%$ & $27.71 \%$ \\
\hline 6. & Xylene & $1.57 \%$ & $16.94 \%$ & $18.51 \%$ & $1.97 \%$ & $17.50 \%$ & $19.47 \%$ & $2.97 \%$ & $18.25 \%$ & $21.22 \%$ \\
\hline 7. & Chlorobenzene & $0.01 \%$ & $0.04 \%$ & $0.05 \%$ & $0.02 \%$ & $0.04 \%$ & $0.06 \%$ & $0.02 \%$ & $0.04 \%$ & $0.06 \%$ \\
\hline
\end{tabular}

\section{Prediction of Pollutant Removal Effect}

The prediction of typical organic pollutant removal is shown in Table 5. The wetland system had different removal efficiency of typical refractory organic compounds (the removal effect was aniline $>$ phenol $>$ xylene $>$ toluene
$>$ benzene $>$ nitrobenzene $>$ chlorobenzene), and filler adsorption and biodegradation played a leading role in the process. The difference of fillers on adsorption performance directly affected the removal efficiency of organic pollutants. Among them, the wetland system filled with a combination of gravel and fly ash had a better removal

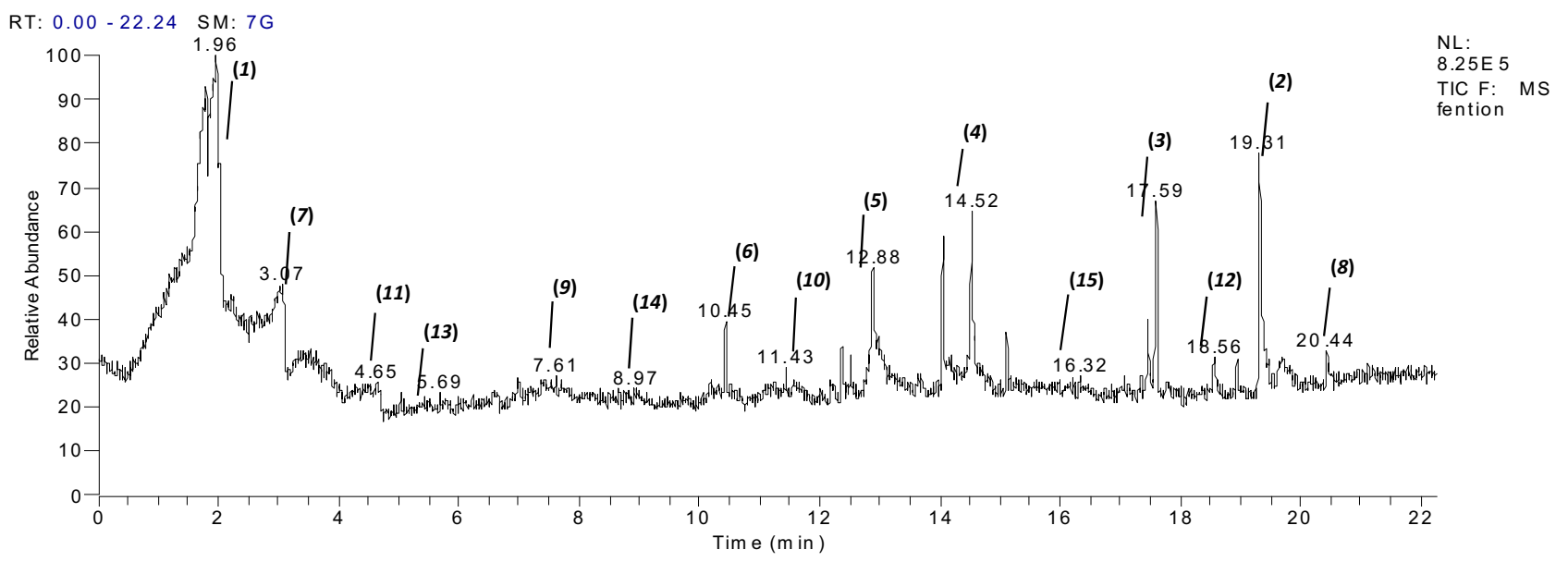

Fig. 2. Distribution of toxic organic pollution in the inputting water of SSFW.

(1) aniline, (2) phenol, (3) dimethylbenzene, (4) toluene, (5) benzene, (6) nitrobenzene, (7) chlorobenzene, ( 8 ) formaldehyde, (9) ethylbenzene, (10) acrylonitrile, (11) carbon tetrachloride, (12) trichloromethane, (13) trichloroethylene, (14) tetrachloroethylene, (15) styrene

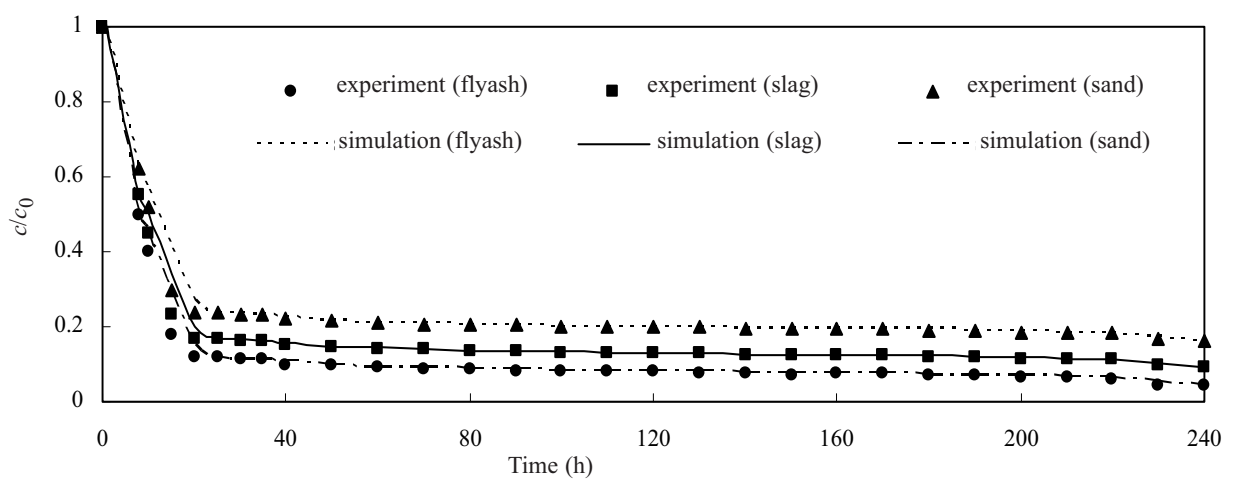

Fig. 3. The simulation and experiment of the removal of Toluene. 
a)

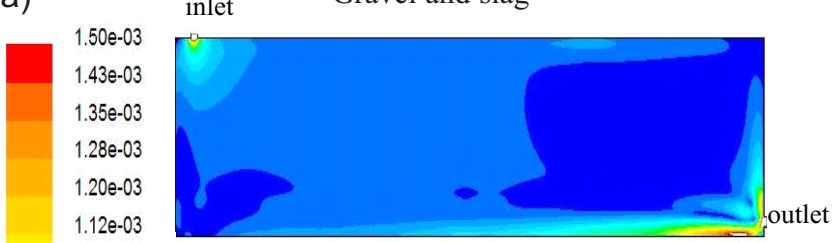

$1.05 e-03$

$9.75 \mathrm{e} .04$

$9.000-04$

$8.25 \mathrm{e}-04$

$7.50 \mathrm{e}-04$

$6.75 \mathrm{e}-04$

$6.00 \mathrm{e} \cdot 04$

$5.25 \mathrm{e}-04$

$4.50 \mathrm{e}-04$

$3.75 \mathrm{e}-04$

$3.00 \mathrm{e}-04$

$2.25 \mathrm{e}-04$

$1.50 \mathrm{e}-04$

$7.50 \mathrm{e}-05$

$0.00 \mathrm{e}+00$ inlet Gravel and fine sand

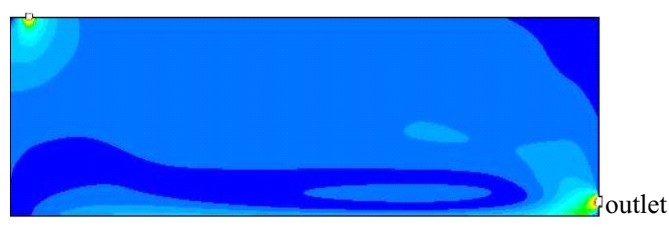

inlet Gravel and flyash

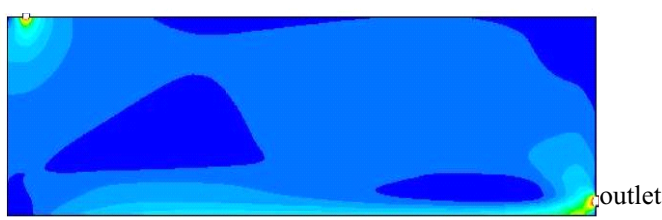

b)

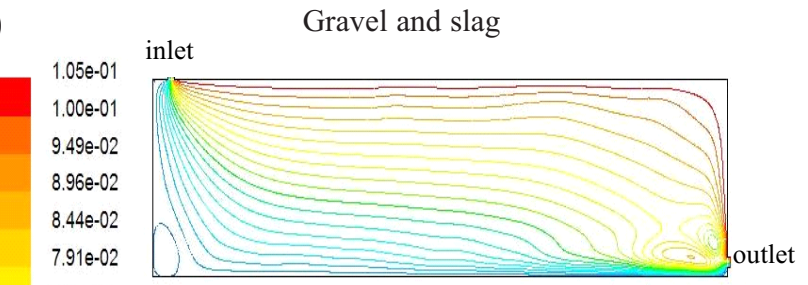

$7.38 \mathrm{e}-02$

$6.85 \mathrm{e}-02$

$6.33 \mathrm{e}-02$

$5.80 \mathrm{e}-02$

$5.27 \mathrm{e}-02$

$4.75 \mathrm{e}-02$

$4.22 \mathrm{e}-02$

$3.69 \mathrm{e}-02$

$3.16 \mathrm{e}-02$

2.64e-02

$2.11 \mathrm{e}-02$

$1.58 \mathrm{e}-02$

$1.05 \mathrm{e}-02$

$5.27 \mathrm{e}-03$

$0.00 e+00$

Fig. 4. Flow field distribution of wetlands with different substrates. (a) streamline distribution (b) contour map.

effect than those filled with gravel and slag, gravel, and fine sand. Taking nitrobenzene as an example, the treatment rate of the wetland system filled with gravel and ash was 5.68\%, while in the other two systems the treatment rates were $4.62 \%$ and $3.91 \%$, respectively. The data indicated that the treatment effect could be improved by extending the retention time and increasing adsorption quantity. Due to the simulation conditions being a natural environment, the biodegradation characteristics of different organic pollutants in the natural environment were different.

So in the design life period, aniline and phenol could be removed by biodegradation and adsorption, while toluene, xylene, benzene, nitrobenzene, could be removed by absorption, part of them also could be biodegraded simultaneously. But for pollutants without obvious biodegradation features, such as chlorobenzene, the removal efficiency was only about $0.04 \%$, indicating that it was only removed by absorption.

\section{Conclusions}

1. The simulation of internal flow field and water quality concentration in the wetland systems could be achieved through the following steps: established mathematical model of migration and transformation of select control organic pollutants in subsurface flow wetland, used porous media model to describe the hydraulic characteristics of subsurface flow constructed wetlands, and coupled mass transfer model with the Monod equation.

2. The model parameters were verified through adsorption and biodegradation experiments, and measured the change of methylbenzene in the subsurface flow wetlands filled with different fillers to verify the model.
Results showed that the model could well simulate the removal effect of pollutants in subsurface flow wetland, and had application value.

3. Under calculation conditions, a backwater region and a rapid channel formed in subsurface flow wetlands of different filler, which shortened the average residence time and reduced the hydraulic efficiency of constructed wetlands, affecting the pollutant removal effect. Therefore, the distribution of flow field could be improved by optimizing the water distribution condition.

4. The removal of seven typical select controls of organic pollutants were predicted, the results showing that the order of removal effect was aniline $>$ phenol $>$ xylene $>$ toluene $>$ benzene $>$ nitrobenzene $>$ chlorobenzene, and the treatment effect of wetland systems could be improved in the means of optimizing filler to improve adsorption capacity and prolong the retention time of organic pollutants.

\section{Acknowledgements}

Funding for this work was provided by the National Natural Science Foundation of China (Grant Nos. 51208358, 51178311), and Tianjin science and technology support project (13ZCZDSF00700).

\section{References}

1. GARCÍA J., AGUIRRE P., BARRAGÁN J., MUJERIEGO R., MATAMOROS V., BAYONA J. M. Effect of key design parameters on the efficiency of horizontal subsurface flow constructed wetlands. Ecol. Eng. 25, 405, 2005. 
2. SAEED T., SUN G. Kinetic modelling of nitrogen and organics removal in vertical and horizontal flow wetlands. Water Res. 45, 3137, 2011.

3. SUN G., SAEED T. Kinetic modelling of organic matter removal in horizontal flow reed beds. Process Biochem. 44, 717, 2009.

4. TANG X.Q., EKE P.E., SCHOLZ M., HUANG S.L. Processes impacting on benzene removal in vertical-flow constructed wetlands. Bioresource Technol. 100, 227, 2009.

5. ROYCHOUDHURY A.N., MERRETT G.L. Redox pathways in a petroleum contaminated shallow sandy aquifer Iron and sulfate reductions. Sci. Total Environ. 366, 262, 2006.

6. LIU L., LU G.H. PCB biodegradation in constructed wetland and contamination risk analysis. Advance in Water Scinece. 14, 79, 2003.

7. GUZZELLA L., ROSCIOLI C., VIGANÒ L., SAHA M., SARKAR S.K., BHATTACHARYA A. Evaluation of the concentration of $\mathrm{HCH}, \mathrm{DDT}, \mathrm{HCB}, \mathrm{PCB}$ and $\mathrm{PAH}$ in the sediments along the lower stretch of Hugli estuary, West Bengal, northeast India. Environment Intemational. 31, 523, 2005.

8. LLORENS E., SAALTINK M. W., GARCÍA J. CWM1 implementation in RetrasoCodeBright: First results using horizontal subsurface flow constructed wetland data. Chem. Eng. J. 166, 224, 2011.

9. LANGERGRABER G., GIRALDI D., MENA J., MEYER D., PEÑA M., TOSCANO A., BROVELLI A., KORKUSUZ E. A. Recent developments in numerical modelling of subsurface flow constructed wetlands. Sci. Total Environ. 407, 3931, 2009.

10. ROUSSEAU D.P.L. Performance of constructed treatment wetlands: model-based evaluation and impact of operation and maintenance. PhD thesis, Ghent University, Belgium, 2005.

11. GAO G., FALCONER R.A., LIN B. Numerical modelling of sedimentebacteria interaction processes in surface waters. Water Res. 45, 1951, 2011.
12. HARRINGTON C., MIKLAS S. Assessment of pre-digested piggery wastewater treatment operations with surface flow integrated constructed wetland systems. Bioresource Technol. 101, 7713, 2010.

13. WANG F.J. Computational fluid dynamics analysis: the principle and application of CFD software, Tsinghua university press, Beijing, 2004.

14. FAN L.W. Hydraulic Characteristic and Removal of Organic Pollutants in the Subsurface Flow Contructed Wetland. Doctoral Thesis, 2008.

15. ZHOU Q.H., HE F., ZHANG L. Characteristics of the microbial communities in the integrated vertical-flow constructed wetlands, Journal of environmental science. 21, 1261, 2009

16. HU N.J., HUANG P., LUO Y.M. X-Ray Absorption Fine Structure (XAFS) study of the effects of $\mathrm{pH}$ on $\mathrm{Pb}$ (II) sorption by soil. Spectrosc. Spect. Anal. 30, 3425, 2010.

17. MORVANNOU A., CHOUBERT J.-M., VANCLOOSTER M., MOLLE P. Solid respirometry to characterize nitrification kinetics: A better insight for modelling nitrogen conversion in vertical flow constructed wetlands. Water Res. 45, 4996, 2011.

18. ZHOU S.G., ZHOU L.X. Adsorption and coprecipitation of dissolved metals with jarosite under conditions simulating sewage sludge bioleaching. Spectrosc. Spect. Anal. 26, 966, 2006.

19. HUANG G.Q., LI X.G., XU S.M. Soil vapor extraction: mechanisms and basic mathematical model. Acta pedologica sinica. 58, 1277, 2007.

20. ZHENG Y.M., LI X G., HUANG G. Q. Mathematic simulation of air flow field in air sparging. Journal of Chemical Industry and Engineering. 58, 1277, 2007.

21. FAN L.W., HAI R.T., LU Z.X. CFD study on effect of catchment area on hydraulic performance of subsurface flow constructed wetland. Journal of Chemical Industry and Engineering. 58, 3024, 2007. 
